\title{
Nutraceuticals in Parkinson's Disease
}

\author{
Liting Hang ${ }^{1,2,3} \cdot$ Adeline Henry Basil $^{1} \cdot$ Kah-Leong Lim ${ }^{1,3,4}$
}

Received: 9 March 2016/Accepted: 19 April 2016/Published online: 4 May 2016

(c) The Author(s) 2016. This article is published with open access at Springerlink.com

\begin{abstract}
Current pharmacological strategies for Parkinson's disease (PD), the most common neurological movement disorder worldwide, are predominantly symptom relieving and are often plagued with undesirable side effects after prolonged treatment. Despite this, they remain as the mainstay treatment for PD due to the lack of better alternatives. Nutraceuticals are compounds derived from natural food sources that have certain therapeutic value and the advent of which has opened doors to the use of alternative strategies to tackle neurodegenerative diseases such as PD. Notably, nutraceuticals are able to position themselves as a "safer" strategy due to the fact that they are naturally derived compounds, therefore possibly having less side effects. Significant efforts have been put into better comprehending the role of nutraceuticals in PD, and we will look at some of them in this review. Broadly speaking, these compounds execute their positive effects via modulating signalling pathways, inhibiting oxidative stress, inflammation and apoptosis, as well as regulating mitochondrial homoeostasis. Importantly, we will highlight how a component of green tea, epigallocatechin-3-gallate (EGCG), confers neuroprotection in PD via its ability to activate AMP kinase and articulate how its beneficial
\end{abstract}

Kah-Leong Lim

phslk1@ nus.edu.sg; kah_leong_lim@nni.com.sg

1 Neurodegeneration Research Laboratory, National

Neuroscience Institute, 11, Jalan Tan Tock Seng,

Singapore 308433 , Singapore

2 Department of Physiology, National University of Singapore, Singapore, Singapore

3 NUS Graduate School for Integrative Sciences and Engineering, Singapore, Singapore

4 Duke-NUS Medical School, Singapore, Singapore effects in PD are possibly due to enhancing mitochondrial quality control.

Keywords AMPK · Mitochondria · Parkin · Parkinson's disease $\cdot$ Neurodegeneration

\section{Introduction}

Parkinson's disease (PD) is the most common neurodegenerative movement disorder currently affecting around 5-6 million predominantly elderly individuals worldwide. $\mathrm{PD}$ is expected to be even more commonplace in the near future as the world's population rapidly ages. In 2030, about 10 million or more are expected to be afflicted with PD (Dorsey et al. 2007). Clinically, the disease is characterized by a constellation of motoric deficits including resting tremor, bradykinesia (slowness in movements), postural instability and rigidity that arises from the depletion of striatal dopamine - a result of the progressive loss of midbrain dopaminergic neurons in the substantia nigra pars compacta $(\mathrm{SNpc})$ that innervate the striatum. This is accompanied by the characteristic neuropathological pattern of eosinophilic intracytoplasmic inclusions known as Lewy bodies (LBs) in surviving neurons in the SN. Notably, $\alpha$-synuclein, a presynaptic protein whose mutations are causative of familial PD, is a major component of LBs (Polymeropoulos et al. 1997). Although a small percentage of PD cases are inheritable as a result of mutations in genes including $\alpha$-synuclein, Parkin, LRRK2, PINK1, and DJ-1, exposure to environmental toxins and pesticides, such as paraquat and rotenone, and synthetic toxins, such as 1-methyl-4-phenyl-1,2,3,6-tetrahydropyridine (MPTP), can also lead to PD (Goldman 2014). To date, the exact disease mechanisms underlying PD pathogenesis are not fully 
understood, but studies have consistently implicated aberrant mitochondrial and protein homoeostasis as key contributors to the development of PD, with oxidative stress likely acting as an important nexus (Lim and Zhang 2013).

At present, therapeutic strategies for the PD patient remain largely symptomatic and more often than not, existing pharmacological treatments come with undesirable side effects. Indeed, pharmacological replacement of dopamine with L-Dopa remains as the gold standard for PD treatment despite its association with diminishing effects and problematic drug-induced dyskinesia after prolonged intake. These inadequacies of the gold standard treatment highlight an urgent need to develop more effective diseasemodifying drugs for PD. In recent years, several alternative approaches to delay the progression of the disease have been considered and coming under the spotlight recently is nutraceuticals. Functional foods and nutritional supplements, which are common sources of nutraceuticals, are beginning to gain international recognition due to the potential health benefits they harbour when consumed as part of a varied diet on a regular basis and at optimal levels. Consequently, both the scientific community and food industry are motivated to exploit these benefits for the prevention and even treatment of chronic ageing diseases, including PD.

\section{Nutraceuticals and PD}

As the word suggests, "nutraceuticals" refers to compounds that are derived from natural sources, and these food or derivatives therein have been clinically substantiated with reasonable scientific evidence to support their beneficial role in the prevention and/or treatment of a particular disease (Chao et al. 2012). It is this very reason that nutraceuticals are more readily accepted by the general populace as a form of treatment. There is a greater tendency to believe that there are fewer side effects associated with compounds derived from natural sources as compared to the many known side effects of synthetic drug compounds.

In the context of PD, several nutraceuticals have been shown to provide neuroprotection in experimental models and may serve as alternatives to synthetic drug compounds like L-Dopa that is known to cause many undesirable side effects. The mechanisms by which they work can be broadly classified into the following themes: (1) reactive oxygen species (ROS)/free radical scavenging; (2) antiinflammation; (3) iron chelation; (4) modulation of cell signalling pathways; (5) anti-apoptosis; and (6) mitochondrial homoeostasis, although several nutraceuticals essentially function via a myriad of mechanistic pathways rather than adhere to a single mechanism (Fig. 1). Table 1 summarizes existing nutraceuticals that have been found to confer neuroprotection in PD. We will discuss a few examples of these below.

The seeds of the Mucuna plant, also affectionately known as dopa bean, are well known for containing LDopa, the go-to drug for treating PD. Although some species of Mucuna contain more L-Dopa than others, the Mucuna plant is generally favoured for the exploitation of L-Dopa due to its relative abundance of which compared to other plant families that have been studied (Patil et al. 2015). Other microbial and chemical means of synthesizing L-Dopa have also been explored (Surwase et al. 2012; Krishnaveni et al. 2009; Ali et al. 2007; Sikander and Ikram ul 2006), but the Mucuna plant has been preferred as it is a natural and inexpensive source, and it provides additional benefits as an antioxidant (Manyam et al. 2004). In fact, a species of Mucuna plant, Mucuna pruriens, has been shown in both the PD mice model and patients to be more effective than L-Dopa without the accompanying increase in dyskinesia (Hussian and Manyam 1997; Katzenschlager et al. 2004).

Apart from the Mucuna plants, there are many other nutraceuticals that appear to be neuroprotective due to their anti-oxidative properties. Such properties are particularly important in the context of PD as several studies have pointed to oxidative stress, which results in ROS generation and inflammation, as a pivotal contributor to age-related neuronal loss in PD (Jenner 1998). An example of a nutraceutical that possesses both anti-oxidative and anti-inflammatory properties is ginsenoside, a phytoestrogen that is extracted from several species of ginseng (Chen et al. 2005). It executes its anti-oxidative properties by maintaining glutathione levels, and its antiinflammatory properties are a result of the regulation of several inflammatory pathways including the ROS-NFKB, JNK, P13K/AKT, ERK, IGF-1 receptor signalling pathways and oestrogen receptor pathway. In addition, ginsenoside also reduces the levels of nigral iron of MPTPtreated mice by regulating the expression of iron transport proteins (Wang et al. 2009b). This is of importance as the build-up of iron in conjunction with ROS at the site of neurodegeneration is thought to constitute a major trigger in neurotoxicity and neuronal demise in PD (Zecca et al. 2004). As such, nutraceuticals like ginsenoside that can inhibit pro-inflammatory and oxidative processes should, in theory, be able to attenuate dopaminergic neuronal damage. Indeed, it has been demonstrated that ginsenoside protects against toxicities and dopaminergic neuronal loss induced by PD toxins including 6-hydroxydopamine (6-OHDA) and MPTP (Chen et al. 2005; Xu et al. 2009). Due to its role in the regulation of JNK signalling, ginsenoside also possesses anti-apoptotic properties. Hence, another postulated mechanism through 
Fig. 1 Nutraceuticals as therapeutics for PD.

Nutraceuticals for PD can be grouped broadly into six themes based on their neuroprotective properties: (1) iron chelation;

(2) cell signalling modulation;

(3) anti-inflammation; (4) antioxidation; (5) anti-apoptosis; and (6) mitochondrial homoeostasis. However, several nutraceuticals hold multiple properties and function via a myriad of mechanistic pathways rather than adhere to a single mechanism

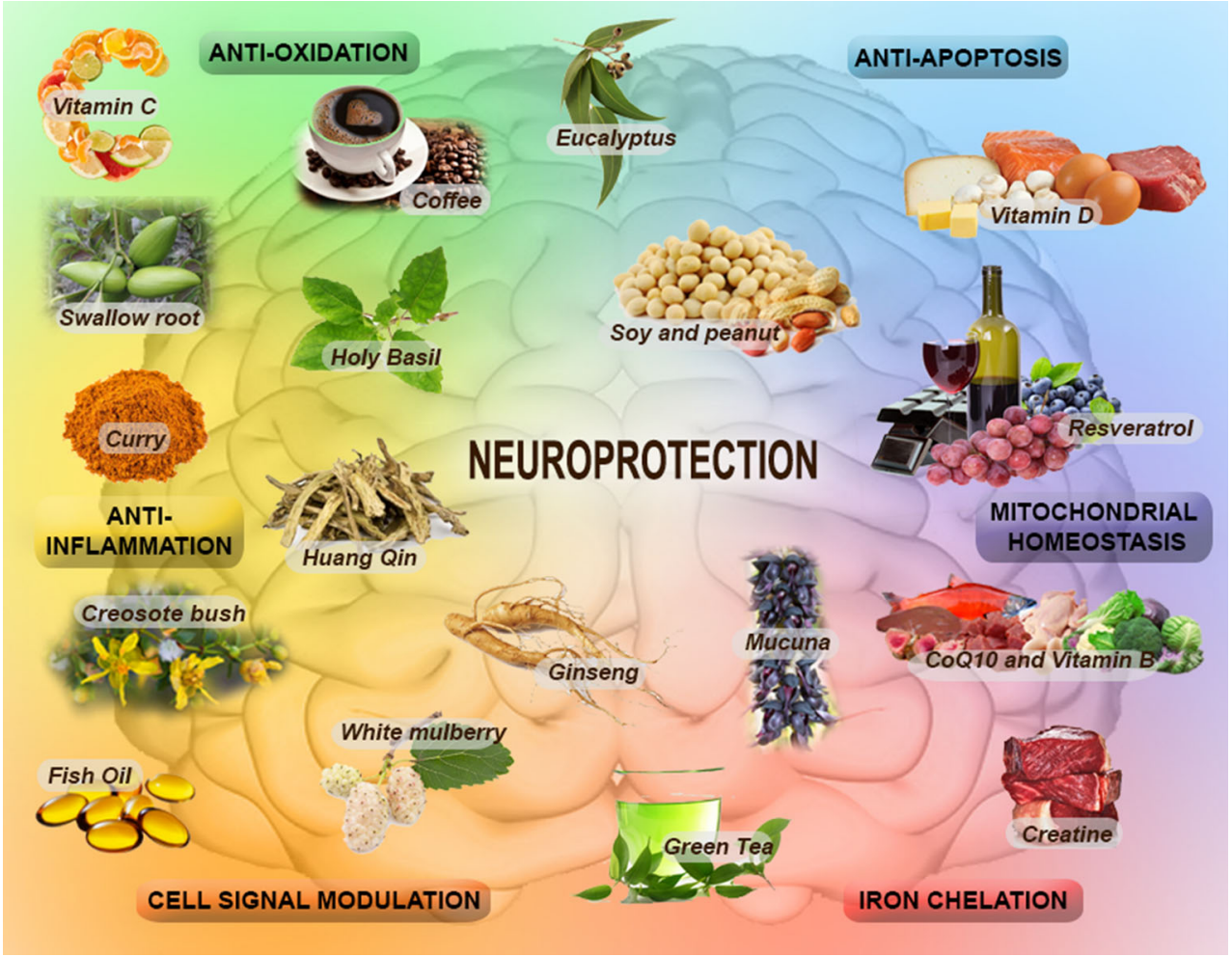

which the neuroprotective effect of ginsenoside is facilitated is its reduction of c-Jun phosphorylation, which prevents pro-apoptotic JNK signalling and dopaminergic neuronal loss during MPTP-induced neurotoxicity (Leppa and Bohmann 1999).

Besides ginseng, dietary soy and peanut products have also been reported to have similar anti-apoptotic effects. Soy and peanut are rich sources of genistein, a phytoestrogen-like ginsenoside. Genistein acts as a tyrosine kinase inhibitor that attenuates protein kinase $\mathrm{C}$ (PKC) activation and thereby downstream apoptotic effects (Kaul et al. 2005; Baluchnejadmojarad et al. 2009). Another potent anti-apoptotic nutraceutical that has been shown to protect against PD toxin-induced neurotoxicity is Ginkobiloba extract EGb 761. EGb 761 prevents the formation of apoptosome and the apoptotic cascade by blocking cytochrome-c release (Liu et al. 2008; Yeh et al. 2009; Nevado et al. 2010). Like ginsenoside, EGb 761 also attenuates the phosphorylation of c-Jun (Shi et al. 2009) and furthermore inhibits the cleavage of caspase-3 (Liu et al. 2008; Shi et al. 2009), thereby preventing DNA fragmentation, a hallmark of apoptosis. By blocking apoptosis through various mechanistic pathways, genistein and EGb 761 were found to attenuate dopaminergic neuronal loss and reduce associated locomotion impairment in 6-OHDA and MPTP mice models (Ahmad et al. 2005; Baluchnejadmojarad et al. 2009; Rojas et al. 2012; Yang et al. 2001).

\section{Nutraceuticals and Mitochondrial Homoeostasis}

As mentioned earlier, aberrant mitochondrial homoeostasis is commonly implicated in PD pathogenesis. Intuitively, one would propose that nutraceuticals that have a role in mitochondrial regulation can potentially mitigate $\mathrm{PD}$ pathology. Coenzyme Q10 $\left(\mathrm{CoQ}_{10}\right)$ is a component of the mitochondrial electron transport chain and participates actively in ATP generation. It is noteworthy to mention that in PD animal models, $\mathrm{CoQ}_{10}$ attenuates MPTP-induced neurotoxicity, possibly due to its unique electron-accepting property, rendering it critical to the electron transfer between mitochondrial complex 1 and other complexes of the electron transport chain (Beal et al. 1998; Cleren et al. 2008). Although it has been proposed as a therapeutic strategy for PD (Shults 2005), clinical trials involving $\mathrm{CoQ}_{10}$ have been conflicting. While one study by Shults et al. reported a dose-dependent reduction in functional decline, another study by Muller et al. observed only mild symptomatic benefit (Shults et al. 2002; Muller et al. 2003). Other nutraceuticals that are reported to be neuroprotective due to their role in preserving mitochondrial complex 1 activity include curcuminoids from turmeric (Jagatha et al. 2008) and the earlier-mentioned Mucuna plant (Manyam et al. 2004). Yet another key player in the maintenance of ATP levels is phosphocreatine, an energy reserve in skeletal muscles and brain. Notably, treatment with creatine appears to rescue parkinsonian phenotypes in 


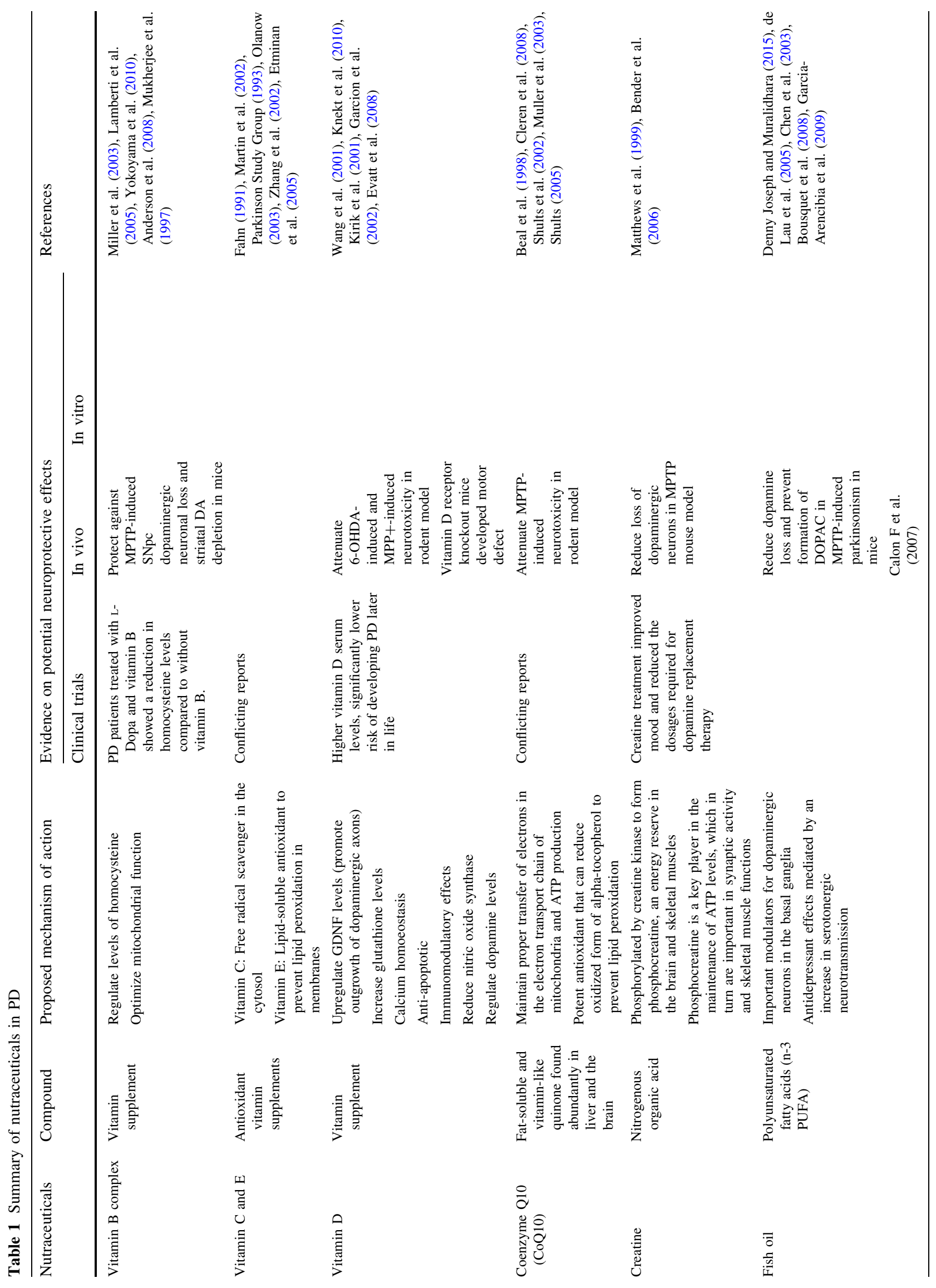




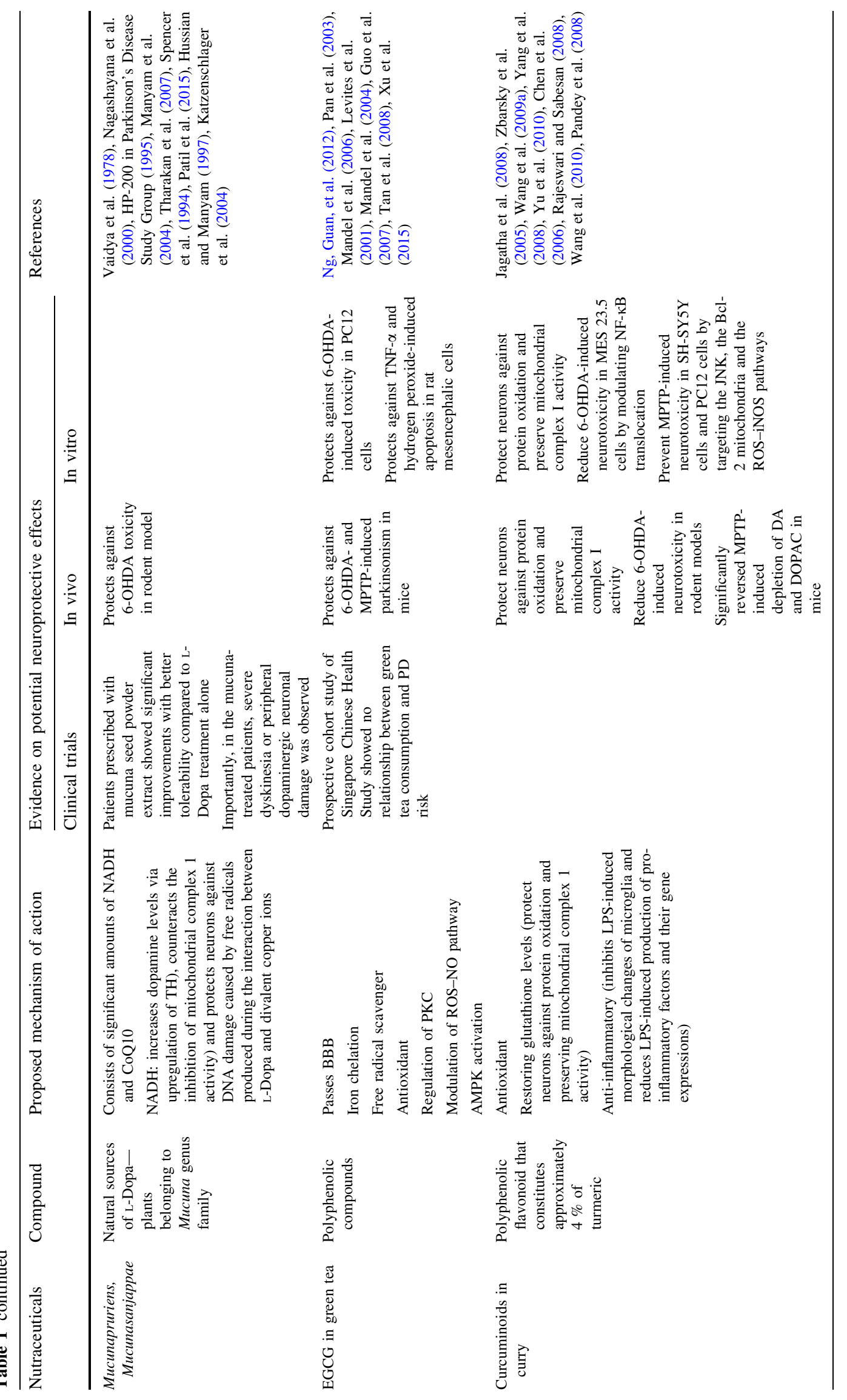




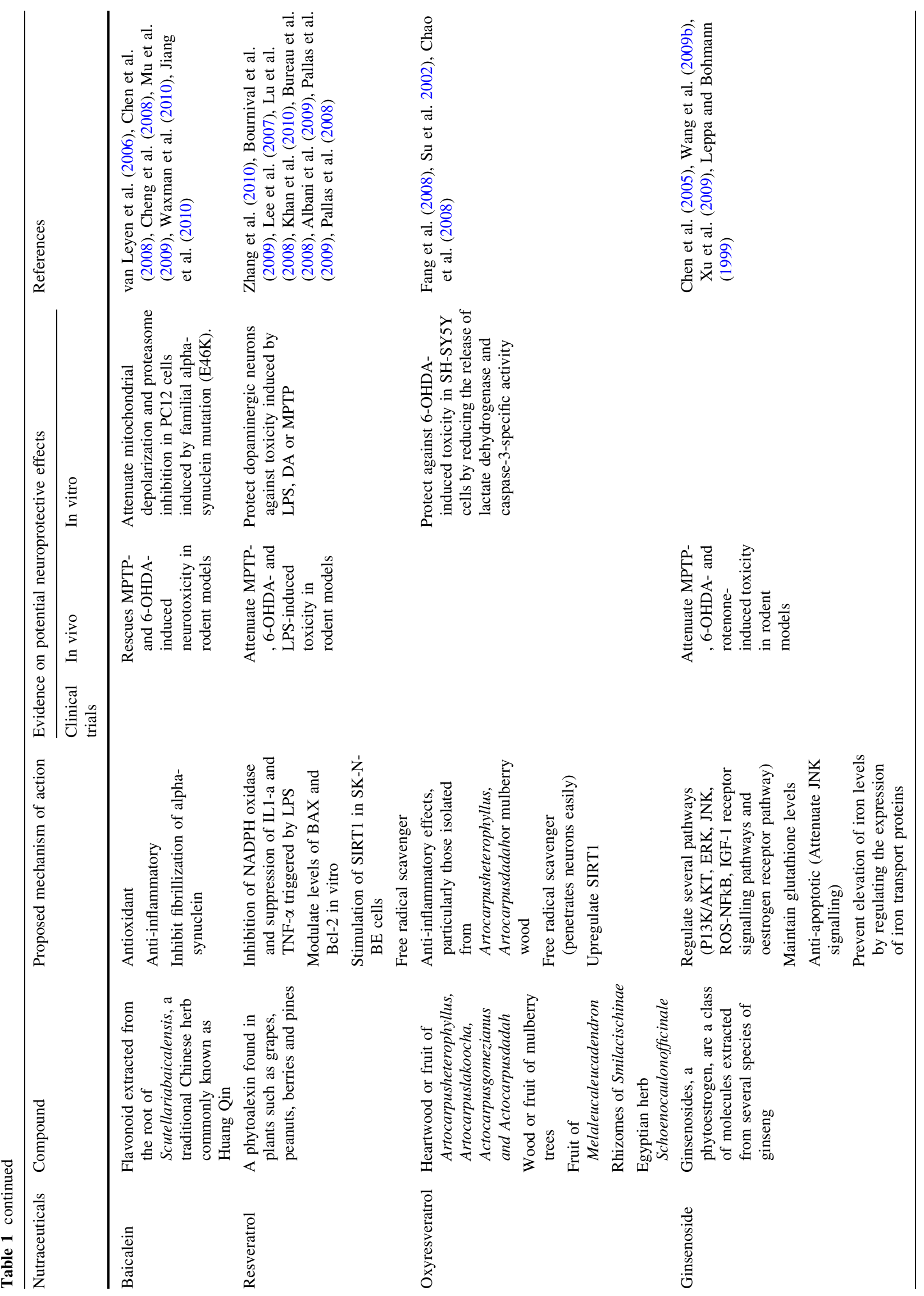




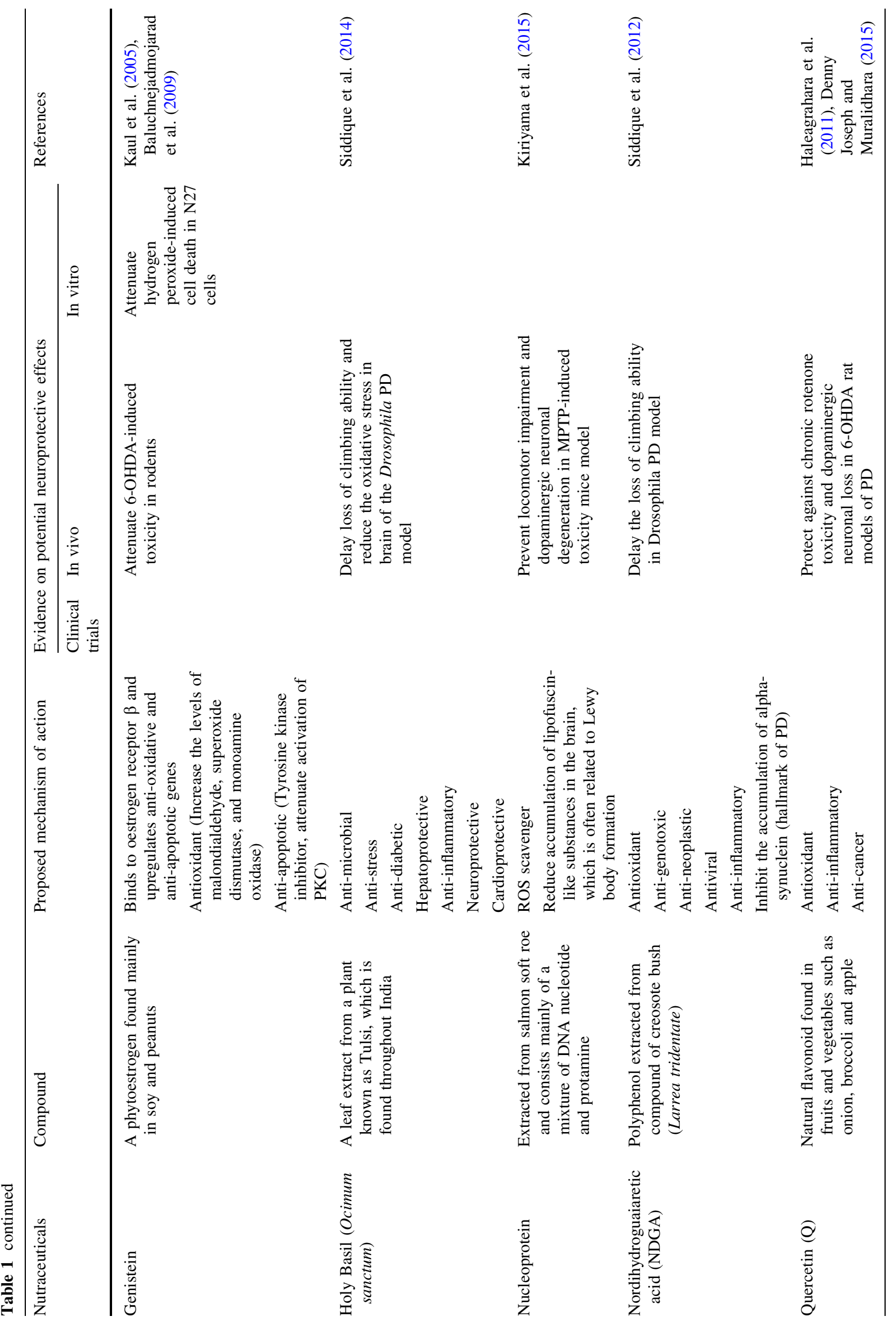




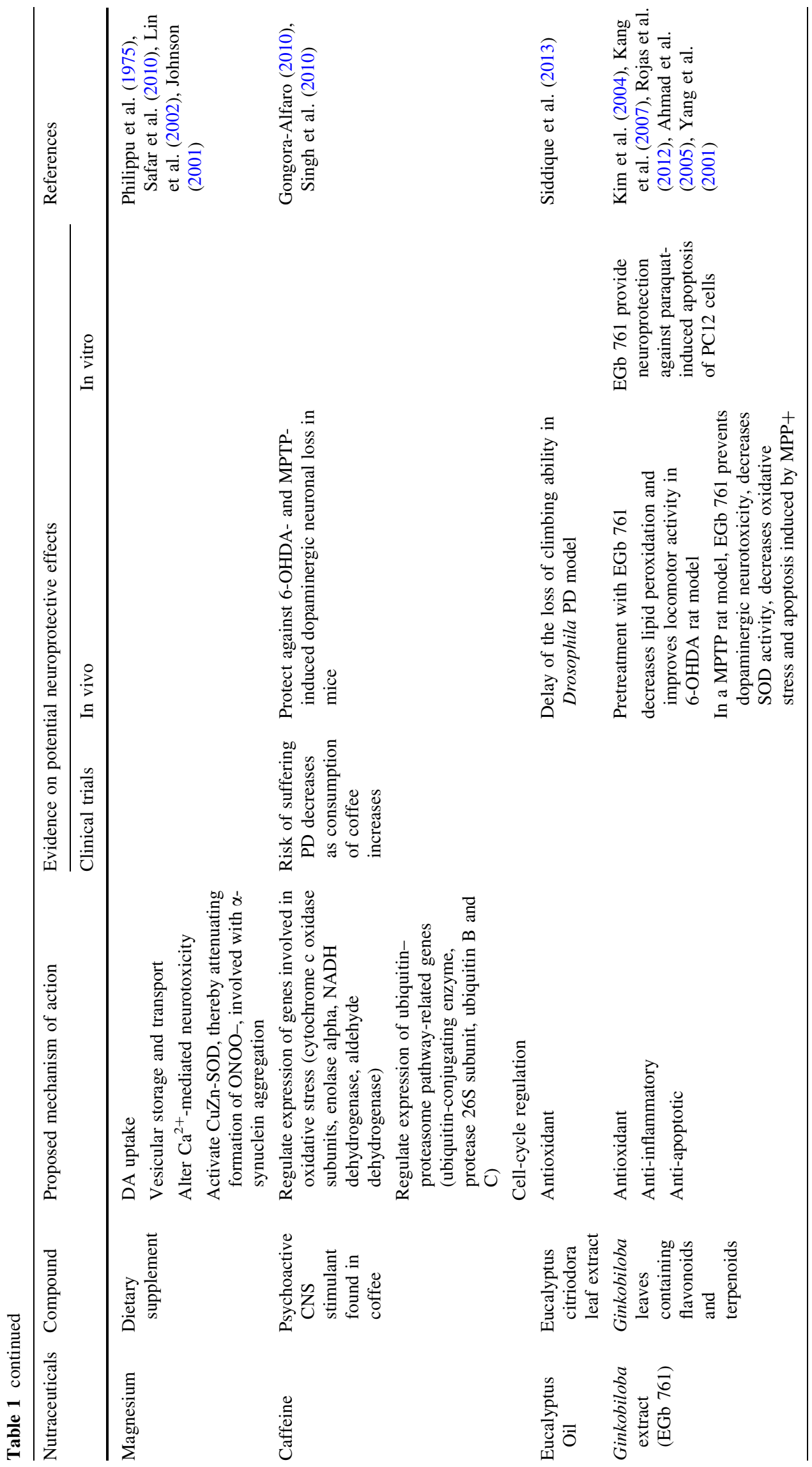




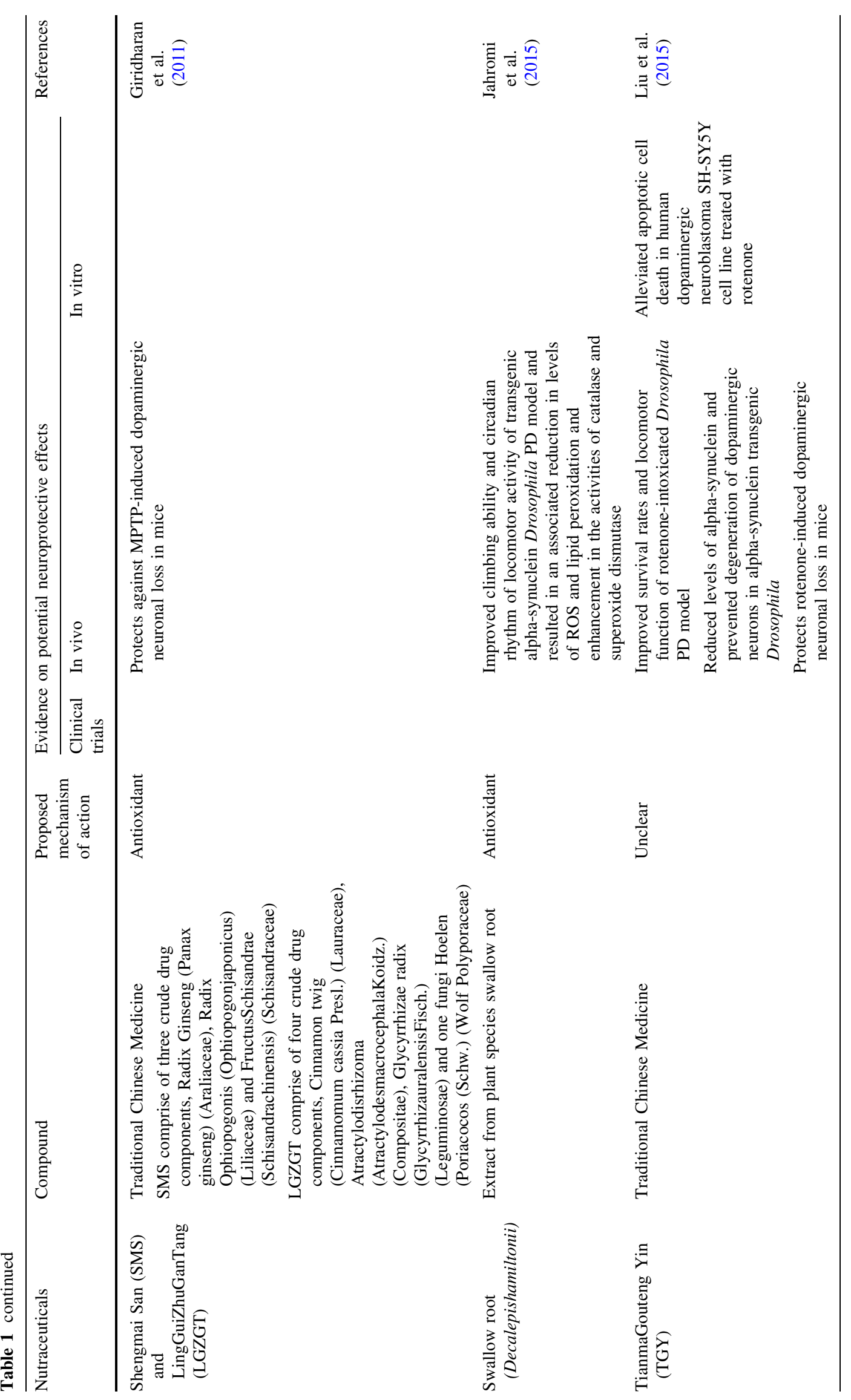


both human subjects and animal models. Specifically, diet supplement of creatine was found to improve the mood and reduce the dosages required for dopamine (DA) replacement therapy in PD patients (Bender et al. 2006), as well as reduce dopaminergic neuronal loss in SNpc of MPTPtreated mice (Matthews et al. 1999). It certainly seems that mitochondrial homoeostasis is a common targeted pathway for nutraceutical therapy notwithstanding the controversy surrounding $\mathrm{CoQ}_{10}$.

Epigallocatechin-3-gallate (EGCG), a main green teaderived catechin, is a nutraceutical that is frequently featured in PD, perhaps due to its numerous putative neuroprotective mechanisms that is not limited to mitochondrial homoeostasis (Pan et al. 2003). These include anti-oxidation, iron chelation, ROS scavenging and anti-apoptotic properties. Moreover, EGCG crosses the blood-brain barrier easily, making it an attractive compound for therapy. Besides the myriad of properties, EGCG has been reported to be an AMPK activator (Spasic et al. 2009; Hwang et al. 2009). It increases cytosolic $\mathrm{Ca}^{2+}$ levels, thereby influencing the activity of $\mathrm{Ca}^{2+}$-/calmodulin-dependent protein kinase kinase $(\mathrm{CaMKK} \beta)$, an upstream kinase of AMPK (Kim et al. 2014). The activation of AMPK in the presence of EGCG is therefore likely to be mediated by CaMKK $\beta$. As discussed below, AMPK activation by EGCG has been demonstrated to be neuroprotective.

\section{AMPK Activation and Neuroprotection}

AMPK is a central energy sensor and regulator that is normally activated in response to diminishing energy supply, e.g. ATP depletion or glucose starvation ( $\mathrm{Li}$ et al. 2012). Given the critical role of AMPK in energy homoeostasis, it is perhaps not surprising to note that AMPK has profound influence on mitochondrial homoeostasis amidst a plethora of metabolic events that it governs. It is well documented that AMPK works through peroxisome proliferator-activated receptor gamma coactivator 1-alpha (PGC-1 $\alpha$ ) to promote mitochondrial biogenesis (Lee et al. 2012). Although the mechanism by which AMPK upregulates PGC-1 $\alpha$ activity remains unclear, studies have suggested that it could directly phosphorylate PGC-1 $\alpha$ (Ng et al. 2012b) or indirectly activate the transcriptional coactivator by promoting its deacetylation through the $\mathrm{NAD}^{+}$-dependent deacetylase SIRT1 (Ng et al. 2012b). Interestingly, a recently identified AMPK target is UNC-51-like kinase 1 (ULK1), a mammalian ortholog of the yeast Atg1 kinase that acts as a key initiator of the autophagy cascade (Carroll et al. 2014; Martin et al. 2014). The activation of ULK1 by AMPK promotes autophagy, including mitophagy. Accordingly, when ULK1 function is impaired, it results in the accumulation of abnormal mitochondria with reduced potential (Martin et al. 2014). Similarly, when the known AMPK-mediated phosphorylation sites on ULK1 are abolished, autophagy is also impaired (Martin et al. 2014), suggesting that the clearance of damaged mitochondria is dependent on the AMPK-ULK1-autophagy pathway. More recently, a study by Toyama et al. reported that AMPK is required for rotenone-induced mitochondrial fission (Toyama et al. 2016), an essential process to isolate damaged mitochondria and promote mitophagy (Twig et al. 2008). Importantly, they identified a novel substrate of AMPK, mitochondrial fission factor (MFF), and found that the presence of non-phosphorylatable MFF resulted in defective mitochondrial fission, further emphasizing the importance of AMPK in regulating mitophagy.

Notwithstanding earlier discussion that AMPK activation helps to maintain mitochondrial quality control and should theoretically promote cellular survival, the role of AMPK activation in neuroprotection remains controversial. Similarly, AMPK activation is also a double-edge sword in the case of PD, promoting neurodegeneration under some circumstances yet aggravating in others. For instance, a study by Kim et al. contradicts a neuroprotective role of AMPK in PD and found that AMPK mediates dopaminergic neuronal atrophy in 6-OHDA-lesioned mice. Moreover, metformin-induced AMPK activation accelerates rather than retards 6-OHDA-induced neuronal loss in these mice (Kim et al. 2013). Subsequently, Xu et al. also observed in a related study similar detrimental effects of AMPK activation in primary neurons treated with 6-OHDA, MPTP or rotenone (Xu et al. 2014). Nonetheless, there are also several reports supporting a neuroprotective role of AMPK in PD. In a recent study by Patil et al., MPTP-treated mice on chronic metformin regimen demonstrated enhanced antioxidant activity and brainderived neurotrophic factor (BDNF) levels, thereby rendering protection against dopaminergic neuronal loss induced by MPP+ (Patil et al. 2015). In a related study, AMPK is activated upon MPTP treatment, and when AMPK activity is downregulated by compound $\mathrm{C}$, neurotoxicity is enhanced (Choi et al. 2010). Supporting this, a recent study demonstrated similar findings albeit in cultured cells exposed to rotenone (Wu et al. 2011). Given that both MPP + and rotenone are complex I inhibitors, the rescue of the in vivo and in vitro $\mathrm{PD}$ models by AMPK activation is consistent with its role in the maintenance of mitochondrial homoeostasis. Importantly, it is also noteworthy to mention that a recent cohort-based study involving 800,000 subjects in a Taiwanese population revealed that metformin-inclusive sulfonylurea therapy significantly reduces PD risk in individuals with type 2 diabetes (Wahlqvist et al. 2012), suggesting the neuroprotective effects of AMPK activation. Collectively, these 
findings suggest that AMPK activation may be beneficial for the disease.

On a related note, we have recently found that EGCG facilitates neuroprotection in PD by mediating mitochondrial regulation via AMPK activation. Using Drosophila as a model, we found that EGCG administration ameliorates the pathological phenotypes of parkin null PD flies, including prominent mitochondrial abnormalities and progressive loss of selected dopaminergic neuronal clusters that are accompanied by an age-dependent decline in locomotor ability ( $\mathrm{Ng}$ et al. 2012a). These are disease phenotypes that bear resemblance to that of human PD (Green and Kroemer 2004; Whitworth et al. 2005). Importantly, the EGCG-mediated protective effects require AMPK as genetic inactivation of AMPK abolishes the neuroprotective effects while subsequent genetic restoration of AMPK and pharmacological activation of AMPK with potent AMPK activators (metformin or AICAR) reproduce these beneficial effects ( $\mathrm{Ng}$ et al. 2012a). In contrast, treatment of parkin null flies with another compound, i.e. Baicalein - an established antioxidant (Shieh et al. 2000), failed to ameliorate the observed parkinsonian phenotypes (unpublished observation). Accordingly, we speculated that AMPK activation rather than anti-oxidation may be involved in EGCG-mediated protective effects. In a similar fashion, Drosophila LRRK2 mutants could be rid of its pathological phenotypes via pharmacological treatment with EGCG, metformin or AICAR or the co-expression of a constitutively active AMPK mutant ( $\mathrm{Ng}$ et al. 2012a), suggesting that this approach may be relevant to different forms of PD. Consistent with our results, Ferretta et al. demonstrated similar benefits using resveratrol (Ferretta et al. 2014), another nutraceutical found in the skin of grapes and berries that is known to be a relatively strong AMPK activator (Dasgupta and Milbrandt 2007). In patient's fibroblasts harbouring parkin mutations, they found that resveratrol increased mitochondrial biogenesis and improved oxidative phosphorylation (Ferretta et al. 2014). While AMPK activation brings about a virtually complete rescue of PD pathological phenotypes in flies, we are currently on the endeavour to dissect precisely how it happens. Nevertheless, existing knowledge of AMPK has shed light on the possible mechanistic pathways via which AMPK-mediated neuroprotection may occur. As mentioned earlier, AMPK is capable of positively regulating mitochondrial biogenesis via PGC- $1 \alpha$ and also mitophagy. This is further supported by the resveratrol-based study by Ferretta et al. that also revealed the ability of AMPK to enhance autophagy flux in parkin-mutant fibroblasts (Ferretta et al. 2014). Hence, it is likely that enhanced mitochondrial biogenesis and/or mitophagy could help in the maintenance of a viable pool of bioenergetically competent mitochondria necessary for dopaminergic neuronal survival. Accordingly, approaches towards promoting these processes may be of therapeutic value for PD.

\section{Conclusion}

As with many other neurodegenerative diseases, PD is a debilitating disorder that gradually robs an individual of his/her fundamental bodily functions. Although much effort has been put into advancing therapeutic strategies for this disease, many conventional and existing treatment options are unfortunately accompanied by several undesirable effects despite their ability to provide symptomatic relief. Fortunately, with the advent of nutraceuticals, an alternative avenue to tackle this seemingly evasive biological problem has been provided. Nutraceuticals, by virtue of their origin from naturally available food or food products, appear to be a favourable treatment option since harnessing therapeutic strategies from natural resources can potentially avoid side effects. As a matter of fact, many of the nutraceuticals discussed in this review have been shown to be not only preventive but also therapeutic for PD. Significantly, we have highlighted in this paper how we and others have demonstrated the ability of green teaderived catechin EGCG to rescue PD pathological outcomes, possibly through enhancing mitochondrial homoeostasis. However, despite many promising reports about the role of nutraceuticals in neuroprotection for PD, we acknowledged that it is early days yet as several mechanistic gaps remain unanswered. Notwithstanding this, the recognition that nutraceuticals might be of therapeutic benefits offers countless opportunities to explore other natural compounds that have not been looked at in terms of their potential neuroprotective roles in PD. For example, ergothioneine (EGT) is a naturally occurring amino acid found in mushrooms that protects mitochondria from oxidative stress (Cheah and Halliwell 2012) and was found to accumulate at significantly lower levels in PD patients compared to healthy controls (Hatano et al. 2015), thus suggesting a therapeutic potential of EGT for the disease. In addition, future research could also direct efforts towards better understanding the effects of nutraceuticals in combination with existing drug therapies for PD patients, in order to derive improved outcomes for the PD patient. The delivery of nutraceuticals could also be optimized in order to maximize their neuroprotective effects. As a parting note, it is hopeful to envisage that one day we would be able to simply modify our diet to prevent or mitigate the progression of this debilitating disease.

Acknowledgments This work was supported by grants from the National Medical Research Council-Translational Clinical Research Program in Parkinson's disease and National Medical Research 
Council-Collaborative Basic Research Grant (LKL). Ms. Hang LT is supported by a graduate scholarship from the National University of Singapore Graduate School for Integrative Sciences and Engineering.

\section{Compliance with Ethical Standards}

Conflict of interest The authors (Hang LT, Basil AH, Lim KL) declare that they have no conflict of interest.

Open Access This article is distributed under the terms of the Creative Commons Attribution 4.0 International License (http://crea tivecommons.org/licenses/by/4.0/), which permits unrestricted use, distribution, and reproduction in any medium, provided you give appropriate credit to the original author(s) and the source, provide a link to the Creative Commons license, and indicate if changes were made.

\section{References}

Ahmad, M., Saleem, S., Ahmad, A. S., Yousuf, S., Ansari, M. A., Khan, M. B., et al. (2005). Ginkgo biloba affords dose-dependent protection against 6-hydroxydopamine-induced parkinsonism in rats: Neurobehavioural, neurochemical and immunohistochemical evidences. Journal of Neurochemistry, 93(1), 94-104. doi:10.1111/j.1471-4159.2005.03000.x.

Albani, D., Polito, L., Batelli, S., De Mauro, S., Fracasso, C., Martelli, G., et al. (2009). The SIRT1 activator resveratrol protects SK-NBE cells from oxidative stress and against toxicity caused by alpha-synuclein or amyloid-beta (1-42) peptide. Journal of Neurochemistry, 110(5), 1445-1456. doi:10.1111/j.1471-4159. 2009.06228.x.

Ali, S., Shultz, J. L., \& Ikram Ul, H. (2007). High performance microbiological transformation of L-tyrosine to L-dopa by Yarrowia lipolytica NRRL-143. BMC Biotechnology, 7, 50. doi:10.1186/1472-6750-7-50.

Anderson, D. W., Bradbury, K. A., \& Schneider, J. S. (2008). Broad neuroprotective profile of nicotinamide in different mouse models of MPTP-induced parkinsonism. European Journal of Neuroscience, 28(3), 610-617. doi:10.1111/j.1460-9568.2008.06356.x.

Baluchnejadmojarad, T., Roghani, M., Nadoushan, M. R., \& Bagheri, M. (2009). Neuroprotective effect of genistein in 6-hydroxydopamine hemi-parkinsonian rat model. Phytotherapy Research, 23(1), 132-135. doi:10.1002/ptr.2564.

Beal, M. F., Matthews, R. T., Tieleman, A., \& Shults, C. W. (1998). Coenzyme Q10 attenuates the 1-methyl-4-phenyl-1,2,3, tetrahydropyridine (MPTP) induced loss of striatal dopamine and dopaminergic axons in aged mice. Brain Research, 783(1), $109-114$.

Bender, A., Koch, W., Elstner, M., Schombacher, Y., Bender, J., Moeschl, M., et al. (2006). Creatine supplementation in Parkinson disease: A placebo-controlled randomized pilot trial. Neurology, 67(7), 1262-1264. doi:10.1212/01.wnl.0000238518. 34389.12 .

Bournival, J., Quessy, P., \& Martinoli, M. G. (2009). Protective effects of resveratrol and quercetin against MPP+-induced oxidative stress act by modulating markers of apoptotic death in dopaminergic neurons. Cellular and Molecular Neurobiology, 29(8), 1169-1180. doi:10.1007/s10571-009-9411-5.

Bousquet, M., Saint-Pierre, M., Julien, C., Salem, N, Jr, Cicchetti, F., \& Calon, F. (2008). Beneficial effects of dietary omega-3 polyunsaturated fatty acid on toxin-induced neuronal degeneration in an animal model of Parkinson's disease. The FASEB Journal, 22(4), 1213-1225. doi:10.1096/fj.07-9677com.
Bureau, G., Longpre, F., \& Martinoli, M. G. (2008). Resveratrol and quercetin, two natural polyphenols, reduce apoptotic neuronal cell death induced by neuroinflammation. Journal of Neuroscience Research, 86(2), 403-410. doi:10.1002/jnr.21503.

Carroll, R. G., Hollville, E., \& Martin, S. J. (2014). Parkin sensitizes toward apoptosis induced by mitochondrial depolarization through promoting degradation of Mcl-1. [Research Support, Non-U.S. Gov't]. Cell Reports, 9(4), 1538-1553. doi:10.1016/j. celrep.2014.10.046.

Chao, J., Yu, M. S., Ho, Y. S., Wang, M., \& Chang, R. C. (2008). Dietary oxyresveratrol prevents parkinsonian mimetic 6-hydroxydopamine neurotoxicity. Free Radical Biology and Medicine, 45(7), 1019-1026. doi:10.1016/j.freeradbiomed.2008.07.002.

Chao, J., Leung, Y., Wang, M., \& Chang, R. C. (2012). Nutraceuticals and their preventive or potential therapeutic value in Parkinson's disease. Nutrition Reviews, 70(7), 373-386. doi:10.1111/j.17534887.2012.00484.x.

Cheah, I. K., \& Halliwell, B. (2012). Ergothioneine; antioxidant potential, physiological function and role in disease. Biochimica et Biophysica Acta (BBA)—Molecular Basis of Disease, 1822(5), 784-793. doi:10.1016/j.bbadis.2011.09.017.

Chen, H., Zhang, S. M., Hernán, M. A., Willett, W. C., \& Ascherio, A. (2003). Dietary intakes of fat and risk of Parkinson's disease. American Journal of Epidemiology, 157(11), 1007-1014. doi:10. 1093/aje/kwg073.

Chen, X. C., Zhou, Y. C., Chen, Y., Zhu, Y. G., Fang, F., \& Chen, L. M. (2005). Ginsenoside Rg1 reduces MPTP-induced substantia nigra neuron loss by suppressing oxidative stress. Acta Pharmacologica Sinica, 26(1), 56-62. doi:10.1111/j.1745-7254.2005. 00019.x.

Chen, J., Tang, X. Q., Zhi, J. L., Cui, Y., Yu, H. M., Tang, E. H., et al. (2006). Curcumin protects PC12 cells against 1-methyl-4phenylpyridinium ion-induced apoptosis by bcl-2-mitochondria-ROS-iNOS pathway. Apoptosis, 11(6), 943-953. doi:10. 1007/s10495-006-6715-5.

Chen, S. F., Hsu, C. W., Huang, W. H., \& Wang, J. Y. (2008). Postinjury baicalein improves histological and functional outcomes and reduces inflammatory cytokines after experimental traumatic brain injury. British Journal of Pharmacology, 155(8), 1279-1296. doi:10.1038/bjp.2008.345.

Cheng, Y., He, G., Mu, X., Zhang, T., Li, X., Hu, J., et al. (2008). Neuroprotective effect of baicalein against MPTP neurotoxicity: Behavioral, biochemical and immunohistochemical profile. Neuroscience Letters, 441(1), 16-20. doi:10.1016/j.neulet.2008. 05.116.

Choi, J. S., Park, C., \& Jeong, J. W. (2010). AMP-activated protein kinase is activated in Parkinson's disease models mediated by 1-methyl-4-phenyl-1,2,3,6-tetrahydropyridine. Biochemical and Biophysical Research Communications, 391(1), 147-151. doi:10.1016/j.bbrc.2009.11.022.

Cleren, C., Yang, L., Lorenzo, B., Calingasan, N. Y., Schomer, A., Sireci, A., et al. (2008). Therapeutic effects of coenzyme Q10 (CoQ10) and reduced CoQ10 in the MPTP model of Parkinsonism. Journal of Neurochemistry, 104(6), 1613-1621. doi:10. 1111/j.1471-4159.2007.05097.x.

Dasgupta, B., \& Milbrandt, J. (2007). Resveratrol stimulates AMP kinase activity in neurons. [Research Support, N.I.H., Extramural Research Support, Non-U.S. Gov't]. Proceedings of the National Academy of Sciences of the United States of America, 104(17), 7217-7222. doi:10.1073/pnas.0610068104.

de Lau, L. M., Bornebroek, M., Witteman, J. C., Hofman, A., Koudstaal, P. J., \& Breteler, M. M. (2005). Dietary fatty acids and the risk of Parkinson disease: The Rotterdam study. Neurology, 64(12), 2040-2045. doi:10.1212/01.wnl. 0000166038.67153.9f. 
Denny Joseph, K. M., \& Muralidhara, (2015). Combined oral supplementation of fish oil and quercetin enhances neuroprotection in a chronic rotenone rat model: Relevance to Parkinson's disease. Neurochemical Research, 40(5), 894-905. doi:10.1007/ s11064-015-1542-0.

Dorsey, E. R., Constantinescu, R., Thompson, J. P., Biglan, K. M., Holloway, R. G., Kieburtz, K., et al. (2007). Projected number of people with Parkinson disease in the most populous nations, 2005 through 2030. Neurology, 68(5), 384-386. doi:10.1212/01. wnl.0000247740.47667.03.

Etminan, M., Gill, S. S., \& Samii, A. (2005). Intake of vitamin E, vitamin C, and carotenoids and the risk of Parkinson's disease: A meta-analysis. Lancet Neurology, 4(6), 362-365. doi:10.1016/ s1474-4422(05)70097-1.

Evatt, M. L., Delong, M. R., Khazai, N., Rosen, A., Triche, S., \& Tangpricha, V. (2008). Prevalence of vitamin $d$ insufficiency in patients with Parkinson disease and Alzheimer disease. Archives of Neurology, 65(10), 1348-1352. doi:10.1001/archneur.65.10. 1348.

Fahn, S. (1991). An open trial of high-dosage antioxidants in early Parkinson's disease. American Journal of Clinical Nutrition, 53(1 Suppl), 380s-382s.

Fang, S. C., Hsu, C. L., \& Yen, G. C. (2008). Anti-inflammatory effects of phenolic compounds isolated from the fruits of Artocarpus heterophyllus. Journal of Agriculture and Food Chemistry, 56(12), 4463-4468. doi:10.1021/jf800444g.

Ferretta, A., Gaballo, A., Tanzarella, P., Piccoli, C., Capitanio, N., Nico, B., et al. (2014). Effect of resveratrol on mitochondrial function: Implications in parkin-associated familiar Parkinson's disease. [Research Support, Non-U.S. Gov't]. Biochimica et Biophysica Acta, 1842(7), 902-915. doi:10.1016/j.bbadis.2014. 02.010 .

Garcia-Arencibia, M., Garcia, C., \& Fernandez-Ruiz, J. (2009). Cannabinoids and Parkinson's disease. CNS \& Neurological Disorders: Drug Targets, 8(6), 432-439.

Garcion, E., Wion-Barbot, N., Montero-Menei, C. N., Berger, F., \& Wion, D. (2002). New clues about vitamin D functions in the nervous system. Trends in Endocrinology and Metabolism, 13(3), 100-105.

Giridharan, V. V., Thandavarayan, R. A., \& Konishi, T. (2011). Effect of Shengmai-san on cognitive performance and cerebral oxidative damage in BALB/c mice. Journal of Medicinal Food, 14(6), 601-609. doi:10.1089/jmf.2010.1362.

Goldman, S. M. (2014). Environmental toxins and Parkinson's disease. Annual Review of Pharmacology and Toxicology, 54, 141-164. doi:10.1146/annurev-pharmtox-011613-135937.

Gongora-Alfaro, J. L. (2010). Caffeine as a preventive drug for Parkinson's disease: Epidemiologic evidence and experimental support. Revista de Neurologia, 50(4), 221-229.

Green, D. R., \& Kroemer, G. (2004). The pathophysiology of mitochondrial cell death. Science, 305(5684), 626-629. doi:10. 1126/science.1099320305/5684/626.

Guo, S., Yan, J., Yang, T., Yang, X., Bezard, E., \& Zhao, B. (2007). Protective effects of green tea polyphenols in the 6-OHDA rat model of Parkinson's disease through inhibition of ROS-NO pathway. Biological Psychiatry, 62(12), 1353-1362. doi:10. 1016/j.biopsych.2007.04.020.

Haleagrahara, N., Siew, C. J., Mitra, N. K., \& Kumari, M. (2011). Neuroprotective effect of bioflavonoid quercetin in 6-hydroxydopamine-induced oxidative stress biomarkers in the rat striatum. Neuroscience Letters, 500(2), 139-143. doi:10.1016/j. neulet.2011.06.021.

Hatano, T., Saiki, S., Okuzumi, A., Mohney, R. P., \& Hattori, N. (2015). Identification of novel biomarkers for Parkinson's disease by metabolomic technologies. Journal of Neurology, Neurosurgery and Psychiatry,. doi:10.1136/jnnp-2014-309676.
HP-200 in Parkinson's Disease Study Group. (1995). An alternative medicine treatment for Parkinson's disease: Results of a multicenter clinical trial. Journal of Alternative and Complementary Medicine, 1(3), 249-255.

Hussian, G., \& Manyam, B. V. (1997). Mucuna pruriens proves more effective than L-DOPA in Parkinson's disease animal model. Phytotherapy Research, 11(6), 419-423. doi:10.1002/ (SICI)1099-1573(199709)11:6<419:AID-PTR120>3.0.CO;2-Q.

Hwang, J. T., Kwon, D. Y., \& Yoon, S. H. (2009). AMP-activated protein kinase: A potential target for the diseases prevention by natural occurring polyphenols. New Biotechnology, 26(1-2), 17-22. doi:10.1016/j.nbt.2009.03.005.

Jagatha, B., Mythri, R. B., Vali, S., \& Bharath, M. M. (2008). Curcumin treatment alleviates the effects of glutathione depletion in vitro and in vivo: Therapeutic implications for Parkinson's disease explained via in silico studies. Free Radical Biology and Medicine, 44(5), 907-917. doi:10.1016/j.freerad biomed.2007.11.011.

Jahromi, S. R., Haddadi, M., Shivanandappa, T., \& Ramesh, S. R. (2015). Attenuation of neuromotor deficits by natural antioxidants of Decalepis hamiltonii in transgenic Drosophila model of Parkinson's disease. Neuroscience, 293, 136-150. doi:10.1016/j. neuroscience.2015.02.048.

Jenner, P. (1998). Oxidative mechanisms in nigral cell death in Parkinson's disease. Movement Disorders, 13(Suppl 1), 24-34.

Jiang, M., Porat-Shliom, Y., Pei, Z., Cheng, Y., Xiang, L., Sommers, K., et al. (2010). Baicalein reduces E46K alpha-synuclein aggregation in vitro and protects cells against $\mathrm{E} 46 \mathrm{~K}$ alpha-synuclein toxicity in cell models of familiar Parkinsonism. Journal of Neurochemistry, 114(2), 419-429. doi:10.1111/j.1471-4159.2010.06752.x.

Johnson, S. (2001). Micronutrient accumulation and depletion in schizophrenia, epilepsy, autism and Parkinson's disease? Medical Hypotheses, 56(5), 641-645. doi:10.1054/mehy.2000.1302.

Kang, X., Chen, J., Xu, Z., Li, H., \& Wang, B. (2007). Protective effects of Ginkgo biloba extract on paraquat-induced apoptosis of PC12 cells. Toxicology in Vitro, 21(6), 1003-1009. doi:10. 1016/j.tiv.2007.02.004

Katzenschlager, R., Evans, A., Manson, A., Patsalos, P. N., Ratnaraj, N., Watt, H., et al. (2004). Mucuna pruriens in Parkinson's disease: A double blind clinical and pharmacological study. Journal of Neurology, Neurosurgery and Psychiatry, 75(12), 1672-1677. doi:10.1136/jnnp.2003.028761.

Kaul, S., Anantharam, V., Yang, Y., Choi, C. J., Kanthasamy, A., \& Kanthasamy, A. G. (2005). Tyrosine phosphorylation regulates the proteolytic activation of protein kinase $\mathrm{C} \delta$ in dopaminergic neuronal cells. Journal of Biological Chemistry, 280(31), 28721-28730. doi:10.1074/jbc.M501092200.

Khan, M. M., Ahmad, A., Ishrat, T., Khan, M. B., Hoda, M. N., Khuwaja, G., et al. (2010). Resveratrol attenuates 6-hydroxydopamine-induced oxidative damage and dopamine depletion in rat model of Parkinson's disease. Brain Research, 1328, 139-151. doi:10.1016/j.brainres.2010.02.031.

Kim, M. S., Lee, J. I., Lee, W. Y., \& Kim, S. E. (2004). Neuroprotective effect of Ginkgo biloba L. extract in a rat model of Parkinson's disease. Phytotherapy Research, 18(8), 663-666. doi:10.1002/ptr.1486.

Kim, T. W., Cho, H. M., Choi, S. Y., Suguira, Y., Hayasaka, T., Setou, M., et al. (2013). (ADP-ribose) polymerase 1 and AMPactivated protein kinase mediate progressive dopaminergic neuronal degeneration in a mouse model of Parkinson's disease. Cell Death and Disease, 4, e919. doi:10.1038/cddis.2013. 447cddis2013447.

Kim, H. S., Quon, M. J., \& Kim, J. A. (2014). New insights into the mechanisms of polyphenols beyond antioxidant properties; lessons from the green tea polyphenol, epigallocatechin 3-gallate. Redox Biol, 2, 187-195. doi:10.1016/j.redox.2013.12.022. 
Kirik, D., Georgievska, B., Rosenblad, C., \& Bjorklund, A. (2001). Delayed infusion of GDNF promotes recovery of motor function in the partial lesion model of Parkinson's disease. European Journal of Neuroscience, 13(8), 1589-1599.

Kiriyama, K., Ohtaki, H., Kobayashi, N., Murai, N., Matsumoto, M., Sasaki, S., et al. (2015). A nucleoprotein-enriched diet suppresses dopaminergic neuronal cell loss and motor deficit in mice with MPTP-induced Parkinson's disease. Journal of Molecular Neuroscience, 55(3), 803-811. doi:10.1007/s12031014-0432-2.

Knekt, P., Kilkkinen, A., Rissanen, H., Marniemi, J., Saaksjarvi, K., \& Heliovaara, M. (2010). Serum vitamin D and the risk of Parkinson disease. Archives of Neurology, 67(7), 808-811. doi:10.1001/archneurol.2010.120.

Krishnaveni, R., Rathod, V., Thakur, M. S., \& Neelgund, Y. F. (2009). Transformation of L-tyrosine to L-dopa by a novel fungus, Acremonium rutilum, under submerged fermentation. Current Microbiology, 58(2), 122-128. doi:10.1007/s00284008-9287-5.

Lamberti, P., Zoccolella, S., Armenise, E., Lamberti, S. V., Fraddosio, A., de Mari, M., et al. (2005). Hyperhomocysteinemia in L-dopa treated Parkinson's disease patients: Effect of cobalamin and folate administration. European Journal of Neurology, 12(5), 365-368. doi:10.1111/j.1468-1331.2004.00973.x.

Lee, M. K., Kang, S. J., Poncz, M., Song, K. J., \& Park, K. S. (2007). Resveratrol protects SH-SY5Y neuroblastoma cells from apoptosis induced by dopamine. Experimental \& Molecular Medicine, 39(3), 376-384. doi:10.1038/emm.2007.42.

Lee, C. W., Wong, L. L., Tse, E. Y., Liu, H. F., Leong, V. Y., Lee, J. M., et al. (2012). AMPK promotes p53 acetylation via phosphorylation and inactivation of SIRT1 in liver cancer cells. [Research Support, Non-U.S. Gov't]. Cancer Research, 72(17), 4394-4404. doi:10.1158/0008-5472.CAN-12-0429.

Leppa, S., \& Bohmann, D. (1999). Diverse functions of JNK signaling and c-Jun in stress response and apoptosis. Oncogene, 18(45), 6158-6162. doi:10.1038/sj.onc.1203173.

Levites, Y., Weinreb, O., Maor, G., Youdim, M. B., \& Mandel, S. (2001). Green tea polyphenol (-)-epigallocatechin-3-gallate prevents $N$-methyl-4-phenyl-1,2,3,6-tetrahydropyridine-induced dopaminergic neurodegeneration. Journal of Neurochemistry, 78(5), 1073-1082.

Li, C., Liu, V. W., Chiu, P. M., Chan, D. W., \& Ngan, H. Y. (2012). Over-expressions of AMPK subunits in ovarian carcinomas with significant clinical implications. [Research Support, Non-U.S. Gov't]. BMC Cancer, 12, 357. doi:10.1186/1471-2407-12-357.

Lim, K. L., \& Zhang, C. W. (2013). Molecular events underlying Parkinson's disease-An interwoven tapestry. Frontiers in Neurology, 4, 33. doi:10.3389/fneur.2013.00033.

Lin, J. Y., Chung, S. Y., Lin, M. C., \& Cheng, F. C. (2002). Effects of magnesium sulfate on energy metabolites and glutamate in the cortex during focal cerebral ischemia and reperfusion in the gerbil monitored by a dual-probe microdialysis technique. Life Sciences, 71(7), 803-811.

Liu, T. J., Yeh, Y. C., Ting, C. T., Lee, W. L., Wang, L. C., Lee, H. W., et al. (2008). Ginkgo biloba extract 761 reduces doxorubicin-induced apoptotic damage in rat hearts and neonatal cardiomyocytes. Cardiovascular Research, 80(2), 227-235. doi:10.1093/cvr/cvn192.

Liu, L.-F., Song, J.-X., Lu, J.-H., Huang, Y.-Y., Zeng, Y., Chen, L.L., et al. (2015). Tianma Gouteng Yin, a Traditional Chinese Medicine decoction, exerts neuroprotective effects in animal and cellular models of Parkinson's disease. Scientific Reports, 5, 16862. doi:10.1038/srep16862.

Lu, K. T., Ko, M. C., Chen, B. Y., Huang, J. C., Hsieh, C. W., Lee, M. C., et al. (2008). Neuroprotective effects of resveratrol on MPTP-induced neuron loss mediated by free radical scavenging.
Journal of Agriculture and Food Chemistry, 56(16), 6910-6913. doi:10.1021/jf8007212.

Mandel, S., Weinreb, O., Amit, T., \& Youdim, M. B. (2004). Cell signaling pathways in the neuroprotective actions of the green tea polyphenol (-)-epigallocatechin-3-gallate: Implications for neurodegenerative diseases. Journal of Neurochemistry, 88(6), $1555-1569$.

Mandel, S., Weinreb, O., Reznichenko, L., Kalfon, L., \& Amit, T. (2006). Green tea catechins as brain-permeable, non toxic iron chelators to "iron out iron" from the brain. Journal of Neural Transmission, 71(Suppl), 249-257.

Manyam, B. V., Dhanasekaran, M., \& Hare, T. A. (2004). Neuroprotective effects of the antiparkinson drug Mucuna pruriens. Phytother Res, 18(9), 706-712. doi:10.1002/ptr.1514.

Martin, A., Youdim, K., Szprengiel, A., Shukitt-Hale, B., \& Joseph, J. (2002). Roles of vitamins $\mathrm{E}$ and $\mathrm{C}$ on neurodegenerative diseases and cognitive performance. Nutrition Reviews, $60(10 \mathrm{Pt} 1)$, 308-326.

Martin, I., Kim, J. W., Dawson, V. L., \& Dawson, T. M. (2014). LRRK2 pathobiology in Parkinson's disease. [Research Support, N.I.H., ExtramuralResearch Support, Non-U.S. Gov'tReview]. Journal of Neurochemistry, 131(5), 554-565. doi:10.1111/jnc. 12949.

Matthews, R. T., Ferrante, R. J., Klivenyi, P., Yang, L., Klein, A. M., Mueller, G., et al. (1999). Creatine and cyclocreatine attenuate MPTP neurotoxicity. Experimental Neurology, 157(1), 142-149. doi:10.1006/exnr.1999.7049.

Miller, J. W., Selhub, J., Nadeau, M. R., Thomas, C. A., Feldman, R. G., \& Wolf, P. A. (2003). Effect of L-dopa on plasma homocysteine in PD patients: Relationship to B-vitamin status. Neurology, 60(7), 1125-1129.

Mu, X., He, G., Cheng, Y., Li, X., Xu, B., \& Du, G. (2009). Baicalein exerts neuroprotective effects in 6-hydroxydopamine-induced experimental parkinsonism in vivo and in vitro. Pharmacology, Biochemistry and Behavior, 92(4), 642-648. doi:10.1016/j.pbb. 2009.03.008.

Mukherjee, S. K., Klaidman, L. K., Yasharel, R., \& Adams, J. D, Jr. (1997). Increased brain NAD prevents neuronal apoptosis in vivo. European Journal of Pharmacology, 330(1), 27-34.

Muller, T., Buttner, T., Gholipour, A. F., \& Kuhn, W. (2003). Coenzyme Q10 supplementation provides mild symptomatic benefit in patients with Parkinson's disease. Neuroscience Letters, 341(3), 201-204.

Nagashayana, N., Sankarankutty, P., Nampoothiri, M. R., Mohan, P. K., \& Mohanakumar, K. P. (2000). Association of L-DOPA with recovery following Ayurveda medication in Parkinson's disease. Journal of the Neurological Sciences, 176(2), 124-127.

Nevado, J., Sanz, R., Sanchez-Rodriguez, C., Garcia-Berrocal, J. R., Martin-Sanz, E., Gonzalez-Garcia, J. A., et al. (2010). Ginkgo biloba extract (EGb761) protects against aging-related caspasemediated apoptosis in rat cochlea. Acta Oto-Laryngologica, 130(10), 1101-1112. doi:10.3109/00016481003713657.

Ng, C. H., Guan, M. S., Koh, C., Ouyang, X., Yu, F., Tan, E. K., et al. (2012a). AMP kinase activation mitigates dopaminergic dysfunction and mitochondrial abnormalities in Drosophila models of Parkinson's disease. Journal of Neuroscience, 32(41), 14311-14317. doi:10.1523/jneurosci.0499-12.2012.

Ng, T. L., Leprivier, G., Robertson, M. D., Chow, C., Martin, M. J., Laderoute, K. R., et al. (2012b). The AMPK stress response pathway mediates anoikis resistance through inhibition of mTOR and suppression of protein synthesis. Cell Death and Differentiation, 19(3), 501-510. doi:10.1038/cdd.2011.119.

Olanow, C. W. (2003). Dietary vitamin E and Parkinson's disease: Something to chew on. Lancet Neurology, 2(2), 74.

Parkinson Study Group (1993). Effects of tocopherol and deprenyl on the progression of disability in early Parkinson's disease. New 
England Journal of Medicine,328(3), 176-183. doi:10.1056/ nejm199301213280305.

Pallas, M., Verdaguer, E., Tajes, M., Gutierrez-Cuesta, J., \& Camins, A. (2008). Modulation of sirtuins: New targets for antiageing. Recent Patents on CNS Drug Discovery, 3(1), 61-69.

Pallas, M., Casadesus, G., Smith, M. A., Coto-Montes, A., Pelegri, C., Vilaplana, J., et al. (2009). Resveratrol and neurodegenerative diseases: Activation of SIRT1 as the potential pathway towards neuroprotection. Current Neurovascular Research, 6(1), 70-81.

Pan, T., Jankovic, J., \& Le, W. (2003). Potential therapeutic properties of green tea polyphenols in Parkinson's disease. Drugs and Aging, 20(10), 711-721.

Pandey, N., Strider, J., Nolan, W. C., Yan, S. X., \& Galvin, J. E. (2008). Curcumin inhibits aggregation of alpha-synuclein. Acta Neuropathologica, 115(4), 479-489. doi:10.1007/s00401-0070332-4.

Patil, R. R., Gholave, A. R., Jadhav, J. P., Yadav, S. R., \& Bapat, V. A. (2015). Mucuna sanjappae Aitawade et Yadav: A new species of Mucuna with promising yield of anti-Parkinson's drug LDOPA. Genetic Resources and Crop Evolution, 62(1), 155-162. doi:10.1007/s10722-014-0164-8.

Philippu, A., Matthaei, H., \& Lentzen, H. (1975). Uptake of dopamine into fractions of pig caudate nucleus homogenates. NaunynSchmiedeberg's Archives of Pharmacology, 287(2), 181-190.

Polymeropoulos, M. H., Lavedan, C., Leroy, E., Ide, S. E., Dehejia, A., Dutra, A., et al. (1997). Mutation in the $\alpha$-synuclein gene identified in families with parkinson's disease. Science, 276(5321), 2045-2047. doi:10.1126/science.276.5321.2045.

Rajeswari, A., \& Sabesan, M. (2008). Inhibition of monoamine oxidase-B by the polyphenolic compound, curcumin and its metabolite tetrahydrocurcumin, in a model of Parkinson's disease induced by MPTP neurodegeneration in mice. Inflammopharmacology, 16(2), 96-99. doi:10.1007/s10787-007-1614-0.

Rojas, P., Montes, P., Rojas, C., Serrano-García, N., \& RojasCastañeda, J. C. (2012). Effect of a phytopharmaceutical medicine, Ginko biloba extract 761, in an animal model of Parkinson's disease: Therapeutic perspectives. Nutrition, 28(11-12), 1081-1088. doi:10.1016/j.nut.2012.03.007.

Safar, M. M., Abdallah, D. M., Arafa, N. M., \& Abdel-Aziz, M. T. (2010). Magnesium supplementation enhances the anticonvulsant potential of valproate in pentylenetetrazol-treated rats. Brain Research, 1334, 58-64. doi:10.1016/j.brainres.2010.03.076.

Shi, C., Zhao, L., Zhu, B., Li, Q., Yew, D. T., Yao, Z., et al. (2009). Dosage effects of EGb761 on hydrogen peroxide-induced cell death in SH-SY5Y cells. Chemico-Biological Interactions, 180(3), 389-397. doi:10.1016/j.cbi.2009.04.008.

Shieh, D. E., Liu, L. T., \& Lin, C. C. (2000). Antioxidant and free radical scavenging effects of baicalein, baicalin and wogonin. Anticancer Research, 20(5A), 2861-2865.

Shults, C. W. (2005). Therapeutic role of coenzyme $\mathrm{Q}(10)$ in Parkinson's disease. Pharmacology \& Therapeutics, 107(1), 120-130. doi:10.1016/j.pharmthera.2005.02.002.

Shults, C. W., Oakes, D., Kieburtz, K., Beal, M. F., Haas, R., Plumb, S., et al. (2002). Effects of coenzyme Q10 in early Parkinson disease: Evidence of slowing of the functional decline. Archives of Neurology, 59(10), 1541-1550.

Siddique, Y. H., Ara, G., Jyoti, S., \& Afzal, M. (2012). The dietary supplementation of nordihydroguaiaretic acid (NDGA) delayed the loss of climbing ability in Drosophila model of Parkinson's disease. Journal of Dietary Supplements, 9(1), 1-8. doi:10.3109/ 19390211.2011 .630716

Siddique, Y. H., Mujtaba, S. F., Jyoti, S., \& Naz, F. (2013). GC-MS analysis of Eucalyptus citriodora leaf extract and its role on the dietary supplementation in transgenic Drosophila model of Parkinson's disease. Food and Chemical Toxicology, 55, 29-35. doi:10.1016/j.fct.2012.12.028.
Siddique, Y. H., Faisal, M., Naz, F., Jyoti, S., \& Rahul, (2014). Role of Ocimum sanctum leaf extract on dietary supplementation in the transgenic Drosophila model of Parkinson's disease. Chinese Journal of Natural, 12(10), 777-781. doi:10.1016/s18755364(14)60118-7.

Sikander, A., \& Ikram ul, H. (2006). Innovative effect of illite on improved microbiological conversion of L-tyrosine to 3,4 dihydroxy phenyl L-alanine (L-DOPA) by Aspergillus oryzae ME2 under acidic reaction conditions. Current Microbiology, 53(5), 351-357. doi:10.1007/s00284-005-0220-x.

Singh, K., Singh, S., Singhal, N. K., Sharma, A., Parmar, D., \& Singh, M. P. (2010). Nicotine- and caffeine-mediated changes in gene expression patterns of MPTP-lesioned mouse striatum: Implications in neuroprotection mechanism. Chemico-Biological Interactions, 185(2), 81-93. doi:10.1016/j.cbi.2010.03.015.

Spasic, M. R., Callaerts, P., \& Norga, K. K. (2009). AMP-activated protein kinase (AMPK) molecular crossroad for metabolic control and survival of neurons. Neuroscientist, 15(4), 309-316. doi:10.1177/1073858408327805.

Spencer, J. P., Jenner, A., Aruoma, O. I., Evans, P. J., Kaur, H., Dexter, D. T., et al. (1994). Intense oxidative DNA damage promoted by $\mathrm{L}$-dopa and its metabolites. Implications for neurodegenerative disease. FEBS Letters, 353(3), 246-250.

Su, B. N., Cuendet, M., Hawthorne, M. E., Kardono, L. B., Riswan, S., Fong, H. H., et al. (2002). Constituents of the bark and twigs of Artocarpus dadah with cyclooxygenase inhibitory activity. Journal of Natural Products, 65(2), 163-169.

Surwase, S. N., Patil, S. A., Jadhav, S. B., \& Jadhav, J. P. (2012). Optimization of L-DOPA production by Brevundimonas sp. SGJ using response surface methodology. Microbial Biotechnology, 5(6), 731-737. doi:10.1111/j.1751-7915.2012.00363.x.

Tan, L. C., Koh, W. P., Yuan, J. M., Wang, R., Au, W. L., Tan, J. H., et al. (2008). Differential effects of black versus green tea on risk of Parkinson's disease in the Singapore Chinese Health Study. American Journal of Epidemiology, 167(5), 553-560. doi:10. 1093/aje/kwm338.

Tharakan, B., Dhanasekaran, M., Mize-Berge, J., \& Manyam, B. V. (2007). Anti-parkinson botanical Mucuna pruriens prevents levodopa induced plasmid and genomic DNA damage. Phytotherapy Research, 21(12), 1124-1126. doi:10.1002/ptr.2219.

Toyama, E. Q., Herzig, S., Courchet, J., Lewis, T. L, Jr, Loson, O. C., Hellberg, K., et al. (2016). Metabolism. AMP-activated protein kinase mediates mitochondrial fission in response to energy stress. Science, 351(6270), 275-281. doi:10.1126/science. aab4138.

Twig, G., Elorza, A., Molina, A. J., Mohamed, H., Wikstrom, J. D., Walzer, G., et al. (2008). Fission and selective fusion govern mitochondrial segregation and elimination by autophagy. EMBO Journal, 27(2), 433-446. doi:10.1038/sj.emboj.7601963.

Vaidya, A. B., Rajagopalan, T. G., Mankodi, N. A., Antarkar, D. S., Tathed, P. S., Purohit, A. V., et al. (1978). Treatment of Parkinson's disease with the cowhage plant-Mucuna pruriens Bak. Neurology India, 26(4), 171-176.

van Leyen, K., Kim, H. Y., Lee, S. R., Jin, G., Arai, K., \& Lo, E. H. (2006). Baicalein and 12/15-lipoxygenase in the ischemic brain. Stroke, 37(12), 3014-3018. doi:10.1161/01.STR.0000249004. 25444.a5.

Wahlqvist, M. L., Lee, M. S., Hsu, C. C., Chuang, S. Y., Lee, J. T., \& Tsai, H. N. (2012). Metformin-inclusive sulfonylurea therapy reduces the risk of Parkinson's disease occurring with Type 2 diabetes in a Taiwanese population cohort. Parkinsonism \& Related Disorders. doi:10.1016/j.parkreldis.2012.03.010.

Wang, J. Y., Wu, J. N., Cherng, T. L., Hoffer, B. J., Chen, H. H., Borlongan, C. V., et al. (2001). Vitamin D(3) attenuates 6-hydroxydopamine-induced neurotoxicity in rats. Brain Research, 904(1), 67-75. 
Wang, J., Du, X. X., Jiang, H., \& Xie, J. X. (2009a). Curcumin attenuates 6-hydroxydopamine-induced cytotoxicity by antioxidation and nuclear factor-kappa B modulation in MES23.5 cells. Biochemical Pharmacology, 78(2), 178-183. doi:10.1016/ j.bcp.2009.03.031.

Wang, J., Xu, H. M., Yang, H. D., Du, X. X., Jiang, H., \& Xie, J. X. (2009b). $\operatorname{Rg} 1$ reduces nigral iron levels of MPTP-treated C57BL6 mice by regulating certain iron transport proteins. Neurochemistry International, 54(1), 43-48. doi:10.1016/j. neuint.2008.10.003.

Wang, M. S., Boddapati, S., Emadi, S., \& Sierks, M. R. (2010). Curcumin reduces alpha-synuclein induced cytotoxicity in Parkinson's disease cell model. BMC Neuroscience, 11, 57. doi:10.1186/1471-2202-11-57.

Waxman, E. A., Emmer, K. L., \& Giasson, B. I. (2010). Residue Glu83 plays a major role in negatively regulating alphasynuclein amyloid formation. Biochemical and Biophysical Research Communications, 391(3), 1415-1420. doi:10.1016/j. bbrc.2009.12.079.

Whitworth, A. J., Theodore, D. A., Greene, J. C., Benes, H., Wes, P. D., \& Pallanck, L. J. (2005). Increased glutathione S-transferase activity rescues dopaminergic neuron loss in a Drosophila model of Parkinson's disease. [Comparative StudyResearch Support, N.I.H., ExtramuralResearch Support, Non-U.S. Gov'tResearch Support, U.S. Gov't, P.H.S.]. Proceedings of the National Academy of Sciences of the United States of America, 102(22), 8024-8029. doi:10.1073/pnas.0501078102.

Wu, Y., Li, X., Zhu, J. X., Xie, W., Le, W., Fan, Z., et al. (2011). Resveratrol-activated AMPK/SIRT1/autophagy in cellular models of Parkinson's disease. Neurosignals, 19(3), 163-174. doi:10. $1159 / 000328516000328516$.

Xu, L., Chen, W. F., \& Wong, M. S. (2009). Ginsenoside Rg1 protects dopaminergic neurons in a rat model of Parkinson's disease through the IGF-I receptor signalling pathway. British Journal of Pharmacology, 158(3), 738-748. doi:10.1111/j.14765381.2009.00361.x.

Xu, Y., Liu, C., Chen, S., Ye, Y., Guo, M., Ren, Q., et al. (2014). Activation of AMPK and inactivation of Akt result in suppression of mTOR-mediated S6K1 and 4E-BP1 pathways leading to neuronal cell death in in vitro models of Parkinson's disease. Cellular Signalling, 26(8), 1680-1689. doi:10.1016/j.cellsig. 2014.04.009S0898-6568(14)00144-2.

Xu, Q., Kanthasamy, A., \& Reddy, M. (2015). (-)-Epigallocatechin3-gallate protects against TNF alpha and hydrogen peroxide induced apoptosis in a cell culture model of Parkinson's disease.
The FASEB Journal, 29(1 Suppl.), 922.9. http://www.fasebj.org/ content/29/1_Supplement/922.9.short.

Yang, S.-F., Wu, Q., Sun, A., Huang, X., \& Shi, J. (2001). Protective effect and mechanism of Ginkgo biloba leaf extracts for Parkinson disease induced by 1-methyl-4-phenyl-1, 2, 3, 6-tetrahydropyridine. Acta Pharmacologica Sinica, 22(12), 1089-1093.

Yang, S., Zhang, D., Yang, Z., Hu, X., Qian, S., Liu, J., et al. (2008). Curcumin protects dopaminergic neuron against LPS induced neurotoxicity in primary rat neuron/glia culture. Neurochemical Research, 33(10), 2044-2053. doi:10.1007/s11064-008-9675-z.

Yeh, Y. C., Liu, T. J., Wang, L. C., Lee, H. W., Ting, C. T., Lee, W. L., et al. (2009). A standardized extract of Ginkgo biloba suppresses doxorubicin-induced oxidative stress and p53-mediated mitochondrial apoptosis in rat testes. British Journal of Pharmacology, 156(1), 48-61. doi:10.1111/j.1476-5381.2008.00042.x.

Yokoyama, H., Kuroiwa, H., Tsukada, T., Uchida, H., Kato, H., \& Araki, T. (2010). Poly(ADP-ribose)polymerase inhibitor can attenuate the neuronal death after 1-methyl-4-phenyl-1,2,3,6tetrahydropyridine-induced neurotoxicity in mice. Journal of Neuroscience Research, 88(7), 1522-1536. doi:10.1002/jnr. 22310.

Yu, S., Zheng, W., Xin, N., Chi, Z. H., Wang, N. Q., Nie, Y. X., et al. (2010). Curcumin prevents dopaminergic neuronal death through inhibition of the c-Jun N-terminal kinase pathway. Rejuvenation Research, 13(1), 55-64. doi:10.1089/rej.2009.0908.

Zbarsky, V., Datla, K. P., Parkar, S., Rai, D. K., Aruoma, O. I., \& Dexter, D. T. (2005). Neuroprotective properties of the natural phenolic antioxidants curcumin and naringenin but not quercetin and fisetin in a 6-OHDA model of Parkinson's disease. Free Radical Research, 39(10), 1119-1125. doi:10.1080/ 10715760500233113.

Zecca, L., Youdim, M. B. H., Riederer, P., Connor, J. R., \& Crichton, R. R. (2004). Iron, brain ageing and neurodegenerative disorders. Nature Reviews Neuroscience, 5(11), 863-873. doi:10.1038/ nrn1537.

Zhang, S. M., Hernan, M. A., Chen, H., Spiegelman, D., Willett, W. C., \& Ascherio, A. (2002). Intakes of vitamins E and C, carotenoids, vitamin supplements, and PD risk. Neurology, 59(8), 1161-1169.

Zhang, F., Shi, J. S., Zhou, H., Wilson, B., Hong, J. S., \& Gao, H. M. (2010). Resveratrol protects dopamine neurons against lipopolysaccharide-induced neurotoxicity through its anti-inflammatory actions. Molecular Pharmacology, 78(3), 466-477. doi:10.1124/mol.110.064535. 